\title{
Radionuclides in Nephrourology, Part 2: Pitfalls and Diagnostic Applications
}

\author{
Andrew T. Taylor \\ Department of Radiology and Imaging Sciences, Emory University School of Medicine, Atlanta, Georgia
}

\begin{abstract}
Learning Objectives: On successful completion of this activity, participants should be able to describe (1) the common clinical indications of suspected obstruction and renovascular hypertension; (2) the status of radionuclide renal imaging in the evaluation of the transplanted kidney and the detection of infection; and (3) potential pitfalls.
\end{abstract}

Financial Disclosure: This review was partially supported by a grant from the National Institutes of Health (NIH/NIDDK R37 DK38842). Andrew T. Taylor is entitled to a share of the royalties for the use of QuantEM software for processing MAG3 renal scans, which was licensed by Emory University to GE Healthcare in 1993. He and his coworkers have subsequently developed in-house, noncommercial software that was used in this study and could affect their financial status. The terms of this arrangement have been reviewed and approved by Emory University in accordance with its conflict-of-interest policies. The author of this article has indicated no other relevant relationships that could be perceived as a real or apparent conflict of interest.

CME Credit: SNMMI is accredited by the Accreditation Council for Continuing Medical Education (ACCME) to sponsor continuing education for physicians. SNMMI designates each JNM continuing education article for a maximum of 2.0 AMA PRA Category 1 Credits. Physicians should claim only credit commensurate with the extent of their participation in the activity. For CE credit, participants can access this activity through the SNMMI website (http:// www.snmmi.org/ce online) through April 2017.

Radionuclide renal scintigraphy provides important functional data to assist in the diagnosis and management of patients with a variety of suspected genitourinary tract problems, but the procedures are underutilized. Maximizing the utility of the available studies (as well as the perception of utility by referring physicians) requires a clear understanding of the clinical question, attention to quality control, acquisition of the essential elements necessary to produce an informed interpretation, and production of a report that presents a coherent impression based on data contained in the report and that specifically addresses the clinical question. To help achieve these goals, part 1 of this review addressed the available radiopharmaceuticals, quality control, and quantitative indices, including the measurement of absolute and relative renal function. Part 2 assumes familiarity with part 1 and focuses on the common clinical indications of suspected obstruction and renovascular hypertension; part 2 also summarizes the status of radionuclide renal imaging in the evaluation of the transplanted kidney and the detection of infection, discusses potential pitfalls, and concludes with suggestions for future research. The series of SAM questions accompanying parts 1 and 2 has been designed to reinforce and extend points made in the review. Although the primary focus is the adult patient, aspects of the review also apply to the pediatric population.

Key Words: diuresis renography; diuretic renography; MAG3; renal obstruction; renovascular hypertension

J Nucl Med 2014; 55:786-798

DOI: 10.2967/jnumed.113.133454

$\mathbf{R}$ adionuclide renal scintigraphy provides important functional data to assist in the diagnosis and management of patients with a variety of suspected genitourinary tract problems; however, the

Received Jul. 9, 2013; revision accepted Jan. 27, 2014.

For correspondence or reprints contact: Andrew T. Taylor, Jr., Emory University Hospital, Division of Nuclear Medicine, 1364 Clifton Rd., NE, Atlanta, GA 30322

E-mail: ataylor@emory.edu

Published online Mar. 3, 2014.

COPYRIGHT (C 2014 by the Society of Nuclear Medicine and Molecular Imaging, Inc. examination is underutilized because referring physicians may have an incomplete knowledge of the advantages and limitations of renal scintigraphy, may not know when or when not to order a study, and may fail to formulate a well-defined clinical question. Moreover, the clinical perception of the utility of renal scintigraphy can vary from institution to institution because of marked differences in scan quality despite the use of the same radiopharmaceutical, comparable equipment, and identical billing. Differences in scan quality are primarily related to differences in physician and technologist training and supervision. The nuclear medicine physician needs to make certain that the clinical question is clearly formulated, the scan is appropriate, and the imaging procedure incorporates the elements required to optimize the study and best answer the clinical question. To help address these goals, part 1 of this review focused on the available radiopharmaceuticals, patient preparation, the utility of quantitative indices, and clearance measurements. Part 2 discusses the common clinical indications of suspected obstruction and renovascular hypertension, briefly summarizes the status of radionuclide renal imaging in the evaluation of the transplanted kidney and the detection of infection, reviews potential pitfalls, and concludes with suggestions for future research. The primary focus is the adult patient, but aspects of the review also apply to the pediatric population.

\section{SUSPECTED OBSTRUCTION (DIURESIS RENOGRAPHY)}

Obstruction to urinary outflow may lead to obstructive uropathy (dilatation of the calices, pelvis, or ureters) and obstructive nephropathy (damage to the parenchyma). The goal of intervention in patients with suspected obstruction is to preserve renal function. The kidneys of almost all patients referred for diuretic renography are either nonobstructed or partially obstructed, with partial obstruction defined as a level of resistance to outflow that, if untreated, will lead to a loss in function; complete obstruction rapidly leads to a nonfunctional kidney (1). The suspicion of urine outflow obstruction is usually based on clinical findings, the incidental detection of a dilated renal collecting system, or diagnosis of previous obstruction in a patient referred for follow-up. Diuresis renography is 
a noninvasive, widely available test that can evaluate renal function and urodynamics in a single procedure. This noninvasive test is based on a high endogenous rate of urine flow stimulated by the administration of furosemide; interpretation is based on washout of the radiopharmaceutical from the collecting system of the upper urinary tract.

\section{Acquisition Protocols, Radiopharmaceutical Choice, and Timing of Furosemide Administration}

The patient should arrive well hydrated and void immediately before the examination since a full bladder may affect upper-tract emptying and give false-positive results (2). Adult and pediatric consensus groups recommend tubular agents for diuresis renography because tubular tracers are much more efficiently extracted by the kidney than ${ }^{99 m} \mathrm{Tc}$-diethylenetriaminepentaacetic acid (DTPA) and washout is therefore easier to evaluate (2-5). Multiple protocols have been used for diuretic renography; they differ in the timing of furosemide administration and in the use of 1 or 2 acquisitions. The 1996 Santa Fe Consensus Report recommended that the time of furosemide be specified; times for furosemide administration include the $\mathrm{F}-15, \mathrm{~F}=0, \mathrm{~F}+2, \mathrm{~F}+5, \mathrm{~F}+10, \mathrm{~F}+20$, and maximum collecting system activity protocols, in which the furosemide is administered 15 min before, simultaneously with, or 2 , 5,10 , or $20 \mathrm{~min}$ after the tracer administration or when activity in the collecting system appears to have reached a maximum (6-15). The F - 15 study is reported to allow better discrimination between obstruction and normal kidneys; however, a recent study reported that an $\mathrm{F}+10$ acquisition with the patient seated gives results comparable or superior to those obtained with the $\mathrm{F}-15$ approach, emphasizing the importance of gravity-assisted drainage regardless of the timing of furosemide (16). The Santa Fe Consensus Report recommended a 35-min acquisition with furosemide administered 20 min into the study (2). A disadvantage of this protocol is that some patients will not complete the study because of a need to void before the acquisition is complete $(6)$.

The single-acquisition study can be divided into 2 separate acquisitions, a 20- to 30-min baseline acquisition followed by patient voiding and then a second 20-min acquisition concurrently with furosemide administration. If the baseline study in adults has normal results, obstruction can be excluded and the furosemide acquisition can be omitted; an unpublished review of 200 adult diuretic renal scans failed to demonstrate a single kidney developing an abnormal renogram after furosemide when the baseline renogram was completely normal. A double-peak pattern indicative of obstruction has been described in pediatric patients after furosemide administration, although the kidneys that became obstructed when the urine flow was high were not completely normal at baseline (17); even for pediatric studies, criteria have been developed that allow the furosemide acquisition to be omitted when the baseline drainage is normal (7).

In summary, the $\mathrm{F}=0$ protocol is most convenient and minimizes imaging time. The $\mathrm{F}+20$ or $\mathrm{F}+30$ protocol allows the direct evaluation of washout of tracer that has accumulated in a dilated collecting system and may allow obstruction to be excluded in a poorly functioning kidney. The $\mathrm{F}-15$ or $\mathrm{F}=0$ protocol may simply demonstrate rising parenchymal activity without visualization of tracer in the collecting system, a pattern that may fail to distinguish between reduced function with obstruction and reduced function in the absence of obstruction. Moreover, administration of furosemide before maximal filling of the collecting system may lead to a prolonged $\mathrm{T} 1 / 2$ (the time it takes for the activity in the kidney to fall to $50 \%$ of its maximum value) and a falsepositive interpretation (15). Each protocol has its advocates, but all appear to give acceptable results in most patients $(5,6,8-13,15)$.

\section{Dose of Furosemide}

The standard dose of furosemide is $0.5 \mathrm{mg} / \mathrm{kg}$ or $40 \mathrm{mg}$ in an adult and $1.0 \mathrm{mg} / \mathrm{kg}$ with a maximum dose of $20 \mathrm{mg}$ in a child $(2,3)$. In young adults with normal renal function, a 40-mg dose of furosemide produces a urine flow rate of approximately $20 \mathrm{~mL} / \mathrm{min}$ within 3-6 min after diuretic administration but maximum diuresis may not be achieved until 15-18 min after injection $(14,18)$. Like ${ }^{99 \mathrm{~m} T c-m e r c a p t o a c e t y l t r i g l y c i n e ~(M A G 3), ~ f u r o s e m i d e ~ i s ~ h i g h l y ~}$ protein-bound; it is not filtered by the glomerulus but is secreted by the proximal tubule, reaching its site of action in the tubular lumen of the thick ascending loop of Henle via the tubular fluid (19). Secretion of furosemide is reduced in kidneys with impaired renal function due to the underlying kidney disease; in addition, secretion of furosemide is further reduced in patients with chronic renal failure due to accumulation of endogenous organic acids that competitively inhibit transport of furosemide by the organic anionic transport system. When there is impaired function, a larger dose of furosemide must be given to compensate for the reduced furosemide secretion and to attain an effective level of diuretic in the tubular fluid (Fig. 1) (19,20). For example, in patients with a glomerular filtration rate (GFR) of approximately $15 \mathrm{~mL} / \mathrm{min} / 1.73 \mathrm{~m}^{2}$, a mean dose of $172 \mathrm{mg}$ of furosemide was required to obtain a maximal diuretic response (21). Because furosemide and ${ }^{99 \mathrm{mTc}-}$ MAG3 share the same organic anion transporter 1, it is reasonable to assume that the standard 40-mg dose of furosemide needs to be doubled if the ${ }^{99 \mathrm{~m}} \mathrm{Tc}-\mathrm{MAG} 3$ clearance is reduced by $50 \%$ or if the serum creatinine is elevated, since an elevated level of serum creatinine usually implies at least a 50\% decrease in GFR and typically a decrease in tubular secretion by a similar amount. In patients with chronic renal insufficiency, an appropriate response to furosemide can be achieved only by administering doses of furosemide sufficient to achieve high enough serum concentrations to provide entry of sufficient amounts of diuretic into the tubular fluid (21). When one kidney has impaired function but overall renal function is normal, there is the possibility that the standard 40-mg dose of furosemide may not achieve an adequate diuretic response in the compromised kidney, leading to an indeterminate or false-positive result. If furosemide is not available, bumetanide is an acceptable alternative; like furosemide, bumetanide requires delivery into the tubular fluid for access to its site of action. The dose of bumetanide is approximately $1 / 40$ the dose of furosemide to achieve an equivalent diuretic response during the first $30 \mathrm{~min}$ after diuretic administration (21).

\section{Adequacy of Diuresis}

A poor diuretic response may indicate dehydration or impaired renal function and result in false-positive or indeterminate findings. Measuring the voided volume alerts the nuclear medicine physician to inadequate diuresis. A patient with normal renal function should produce about $200-300 \mathrm{~mL}$ of urine in 20-30 min after the administration of $40 \mathrm{mg}$ of furosemide (18). As renal function decreases, the urine flow rate typically decreases, but urine flow rates of as high as $4 \mathrm{~mL} / \mathrm{min}$ have been reported for some patients with creatinine clearances reduced to $20 \%$ of normal $(14,22)$, occasionally allowing obstruction to be excluded in nonobstructed kidneys with poor renal function, particularly if the renal pelvis is not excessively dilated. As renal function further deteriorates, an abnormal diuretic response cannot reliably distinguish obstruction from 


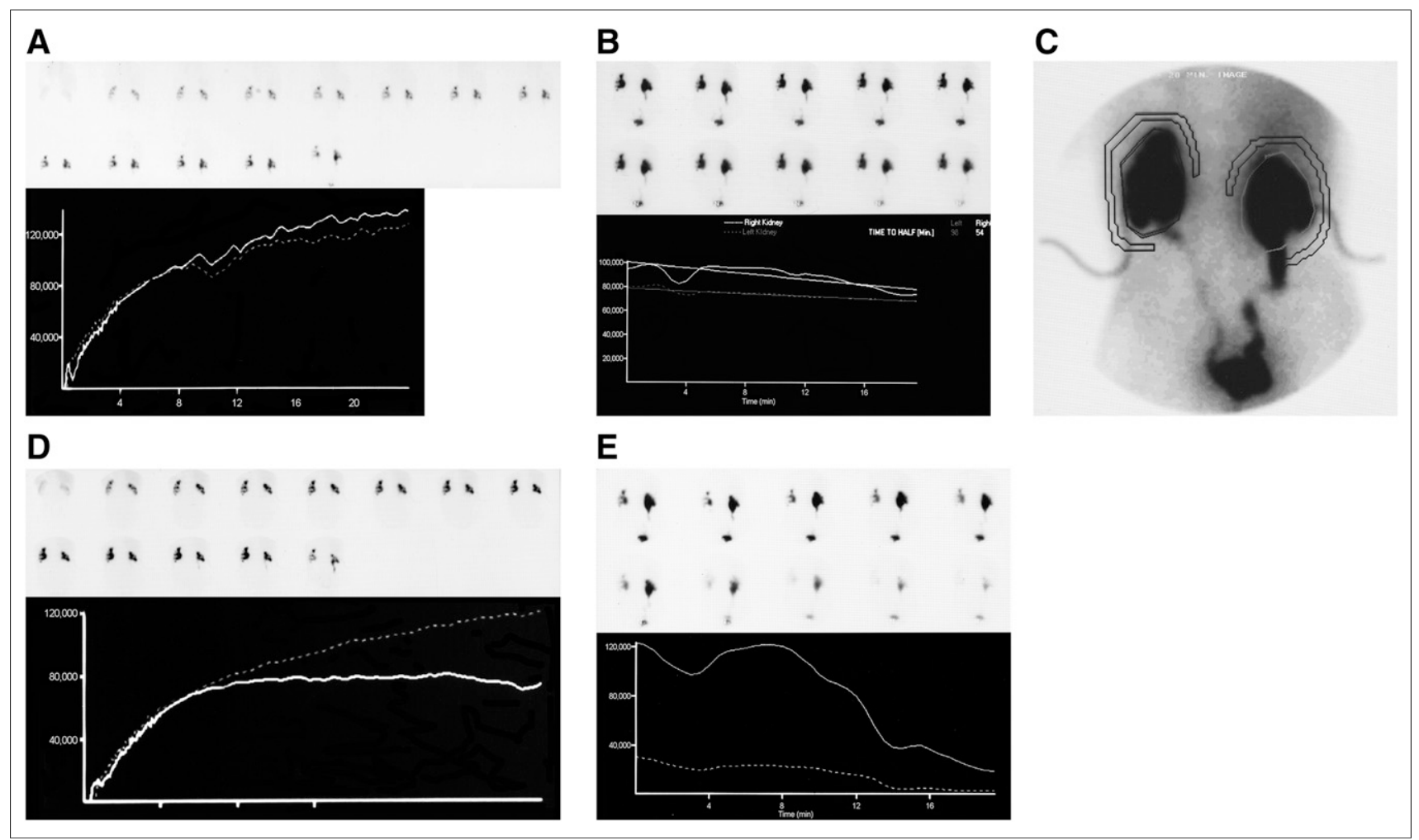

FIGURE 1. A 77-y-old man with a complicated history had bilateral obstruction resulting in placement of bilateral nephrostomy tubes. Four years later, he was voiding normally as well as draining from nephrostomy tubes. 99mTc-MAG3 scan was obtained to evaluate drainage. His serum creatinine was $2.0 \mathrm{mg} / \mathrm{dL}$ and had been stable for several years. (A) Baseline whole-kidney renogram (sequential 2-min ${ }^{99 m T c-M A G 3 ~ i m a g e s ~}$ obtained for $24 \mathrm{~min}$ ) shows prolonged time to peak activity bilaterally. Relative function was $53 \%$ on left and $47 \%$ on right. Camera-based 99mTc-MAG3 clearance was $113 \mathrm{~mL} / \mathrm{min} / 1.73 \mathrm{~m}^{2}$, compared with reference range of $238-433 \mathrm{~mL} / \mathrm{min} / 1.73 \mathrm{~m}^{2}$. (B) Sequential 2-min images obtained after $40 \mathrm{mg}$ of furosemide show pelvic retention. Time-activity curve shows minimal excretion; T1/2 measured 98 min for left kidney and $54 \mathrm{~min}$ for right kidney. (C) Even though appearance of images and curves was consistent with obstruction, patient was clearly not obstructed since nephrostomy tubes had not been clamped. By increasing image intensity on computer, percutaneous nephrostomy tubes and ureters could be visualized although percutaneous nephrostomy tubes had not been apparent on standard image display. (D) Patient returned for repeated study, and nephrostomy tubes were clamped. Sequential 2-min 99mTc-MAG3 images were again obtained for 24 min; last image in sequence is postvoid image. Whole-kidney renogram (lower left panel) shows prolonged time to peak activity bilaterally. Relative function was $54 \%$ on left and $46 \%$ on right. Camera-based ${ }^{99 m T c-M A G 3 ~ c l e a r a n c e ~ w a s ~} 84 \mathrm{~mL} / \mathrm{min} / 1.73 \mathrm{~m}^{2}$. (E) Patient received $80 \mathrm{mg}$ of furosemide because of inadequate response to $40 \mathrm{mg}$ of furosemide on initial study. Sequential 2-min images obtained for $20 \mathrm{~min}$ after furosemide administration and time-activity curves demonstrate prompt washout of tracer from both kidneys; much of the activity in left kidney had drained on postvoid image (last image in sequence); $\mathrm{T} 1 / 2$ was $12 \mathrm{~min}$ for left kidney and $13 \mathrm{~min}$ for right kidney. Obstruction could be excluded, and nephrostomy tubes were pulled. Patient's renal function has remained stable. (Reprinted with permission of (23).)

a poorly functioning kidney that failed to respond to furosemide. Conversely, if the kidney has a near-normal clearance, it should have a good diuretic response; in this setting, marked parenchymal and collecting system retention after furosemide is much more suggestive of obstruction.

\section{Region-of-Interest (ROI) Selection for Diuretic Portion of Study}

For the diuretic portion of the study, some physicians assign an ROI over the whole kidney whereas others recommend placing the ROI around the dilated collecting system $(2,5,15)$. Data indicate that placement of the ROI around the dilated pelvis and collecting system rather than the whole kidney better assesses the response to furosemide $(15,23,24)$, but $\mathrm{T}^{1} / 2$ values are also dependent on the method of calculation.

\section{Patients with Nephrostomy or Urinary Diversion}

Patients with a urinary diversion are at an increased risk of reflux, making the evaluation of washout and suspected obstruction more problematic. There are 3 main types of urinary diversion procedures: an ileal conduit urinary diversion, an Indiana pouch reservoir, and construction of a neobladder with drainage to the urethra. All 3 may reflux, although reflux is more common with an ileal conduit. When feasible, a urinary diversion should be catheterized before the study to empty any residual urine and the catheter should be left in place during the study to allow drainage and minimize the possibility that reflux will compromise interpretation of the study (Fig. 2) (25). Patients with a nephrostomy represent a special situation. Depending on the clinical question, it may be necessary to clamp the nephrostomy before the study (Fig. 1). The decision to clamp or not to clamp the nephrostomy has to be addressed before the study and may require consultation with the referring urologist.

\section{Acute Renal Colic}

Unenhanced (noncontrast) helical CT has rapidly gained acceptance as the procedure of choice for patients presenting with acute renal colic. With unenhanced helical CT, the risk of contrast 


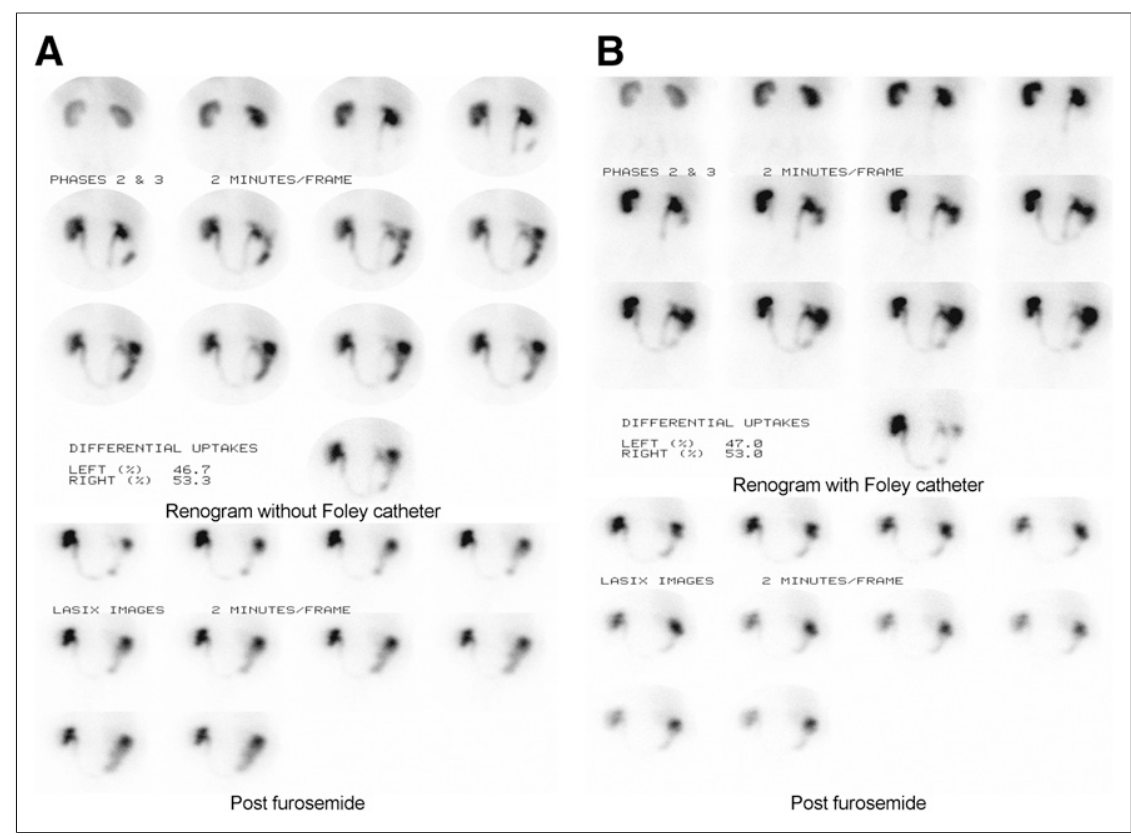

FIGURE 2. A 57-y-old man with prostate adenocarcinoma had undergone radical cystoprostatectomy and urinary diversion with construction of neobladder from piece of large intestine. Abdominal CT performed 2 y after resection showed mild left-sided hydronephrosis. (A) Renogram after administration of $395.9 \mathrm{MBq}(10.1 \mathrm{mCi})$ of ${ }^{99 m}$ Tc-MAG3 showed persistent activity within left urinary collecting system; $40 \mathrm{mg}$ of furosemide (Lasix; Sanofi-Aventis) were subsequently administered followed by 20 -min acquisition, which showed minimal clearance from collecting system and abnormal T1/2 of 19 min for left kidney; however, poor drainage may have resulted from relatively high pressure within reservoir and ureteral reflux. (B) Baseline renogram was repeated with $355.6 \mathrm{MBq}(9.61 \mathrm{mCi})$ of $99 \mathrm{mTc}-\mathrm{MAG} 3$ and again shows accumulation of activity within left collecting system; right kidney is not obstructed. To minimize possibility of reflux, Foley catheter was placed into ileostomy. Postfurosemide renogram showed complete emptying of left collecting system with half-life of $9.9 \mathrm{~min}$, excluding obstruction. In adults with urinary diversion, incidence of reflux is relatively high. Given ease of placing indwelling catheter into ileostomy, protocol for diuretic renogram should include catheterization to maximize diagnostic accuracy. (Reprinted with permission of (25).)

material can be avoided, which is particularly important for patients with renal insufficiency, diabetes, dehydration, or allergy to iodinated contrast agents; moreover, stone size can be accurately ascertained, and the correct diagnosis can be made in approximately $50 \%$ of patients whose symptoms are not caused by a renal stone.

Knowledge of the size of the obstructing calculus is important because calculi smaller than $5 \mathrm{~mm}$ generally pass spontaneously; as the size of the calculus increases, spontaneous passage becomes less likely. Many calculi between 3 and $8 \mathrm{~mm}$ in size are followed conservatively in the hope of spontaneous passage, and patients may be managed on an outpatient basis. Despite its advantages, unenhanced helical CT cannot determine the functional status of the kidney. Larger stones $(5-8 \mathrm{~mm})$ may not be associated with high-grade obstruction and can be managed conservatively, whereas some small stones (3-5 $\mathrm{mm}$ ) do result in high-grade obstruction and may require more aggressive management. The addition of a diuretic renal scan while the patient is in the emergency room can determine the presence or absence of obstruction and has been shown to direct patient management; in one study, the scan changed the decision to admit or discharge the patient in $30 \%$ of cases $(11,12,26,27)$. If additional data show that a renal scan leads to better patient outcomes or reduced medical costs, then diuresis renography could have an increasingly important role in the management of patients presenting with acute renal colic.

\section{Diagnostic Criteria}

The $\mathrm{T}^{1} \frac{2}{2}$ provides a single and superficially simple heuristic to diagnose an obstructed kidney, that is, if the $T^{1} / 2$ is greater than $20 \mathrm{~min}$, the kidney is obstructed. Unfortunately, this single rule used in isolation is insufficient and may well be misleading. At the other extreme, a current expert system incorporates 116 different rules incorporating a variety of potential clinical and quantitative parameters to distinguish between an obstructed and a nonobstructed kidney (28). In an attempt to provide guidance, a predictive model was used to identify the most useful variables for the evaluation of suspected obstruction (23). In a dual-acquisition baseline-plusfurosemide protocol, the postvoid-tomaximum ratio was the single most important variable for excluding obstruction on the baseline acquisition, whereas the time to half-maximum counts in a pelvic ROI and the renal counts in the last minute of furosemide acquisition divided by the maximum renal counts in the baseline acquisition were the critical variables after furosemide administration (analysis of postvoid data after furosemide in this study would have been desirable, but postvoid furosemide data were not available) (23). In summary, the diagnostic process requires an analysis of the images, curves, and quantitative indices as well as any relevant clinical information or diagnostic studies that may be available. Specific criteria that can assist in distinguishing between an obstructed and nonobstructed kidney are further discussed below.

$T^{1 / 2}$. Drainage is conventionally assessed by measuring the $T^{1 / 2}$ after furosemide administration; this parameter is more reliable when the ROI used to calculate the $T^{1 / 2}$ is restricted to retained activity in the collecting system rather than assigned around the whole kidney $(15,23,24)$. T1 12 measurements are also affected by the choice of radiopharmaceutical, the delay between administering the radiopharmaceutical and administering furosemide, the method of hydration, the bladder volume, the presence or absence of a bladder catheter, the dose of furosemide, the interval used to make the measurement, and the algorithm used to fit the washout curve for calculating the $\mathrm{T}^{1} 1 / 2(2,4,5,23,24)$. For these reasons, values for the $\mathrm{T}^{1} / 2$ are not standardized and tend to be institution-specific. Nevertheless, there is general agreement that prompt clearance of the radiopharmaceutical from the renal collecting system with a $\mathrm{T}^{1 / 2}$ under 10 min excludes obstruction; however, a prolonged $\mathrm{T}^{1} / 2$ should never be the sole criterion for determining the presence of obstruction.

Gravity-Assisted Drainage, Postvoid Images, and Alternatives to $T^{1} / 2$. Recent pediatric consensus reports have concluded that the $\mathrm{T} 1 / 2$ is not acceptable as an isolated tool for evaluating washout $(3,29)$. Techniques that consider renal function, use gravity-assisted drainage, and incorporate postvoid images appear to provide more robust alternatives $(3,15,10,23,29-31)$. If a large proportion of the 
radiopharmaceutical remains in the collecting system at the end of the study, the patient should be asked to get off the table, stand up, walk around for a few minutes, void, and get back on the table to maintain a consistent geometry for a postvoid image. Infants should be held in an upright position for about $5 \mathrm{~min}$ to allow gravity to assist drainage before another image of the kidney is obtained $(3,10)$. Measurements that quantitate postvoid emptying or gravityassisted drainage may facilitate interpretation of the study $(10,30)$. Drainage can be quantitated by measuring output efficiency, the residual or postvoid renal counts normalized to the 1- to 2-min renal counts (normalized residual activity), or the residual or postvoid renal counts normalized to the maximum counts $(23,31,32)$. In summary, a measure of postvoid emptying appears to provide better discrimination between obstructed, equivocal, and nonobstructed kidneys in children and adults than the $\mathrm{T}^{1} / 2$ alone and was a recommended procedure in a recent guideline on structured reporting in diuresis renography $(3,5,10,23,30-32)$.

Relative Renal Function. Obstruction usually causes a loss of function in the affected kidney unless the obstruction is acute. In a patient with suspected unilateral chronic obstruction, the likelihood of obstruction is reduced when the relative renal function in the current study is essentially unchanged from the relative function obtained in the preceding study even if the quantitative data such as the $T^{1} / 2$ are abnormal for the kidney in question. In these cases, it may be appropriate to continue to observe the patient and repeat the study at a later date. An alternative is the use of sonography as a complementary study to determine whether the size of the renal pelvis is increasing over time; an increase in the size of the renal pelvis is an indirect indication of obstruction and merits further evaluation.

Tissue Tracer Transit. Tissue tracer transit has been proposed as a parameter to help distinguish between hydronephrotic kidneys that require an intervention to preserve renal function and hydronephrotic kidneys that do not require intervention $(33,34)$. Tissue tracer transit refers to the transit of ${ }^{99} \mathrm{~m}$ Tc-MAG3 from the renal parenchyma to the renal pelvis; delayed tissue tracer transit is defined by a photopenic renal pelvis between the second or third and eighth or tenth minute after injection with stable or increasing parenchymal concentration. In a retrospective series, abnormal values were associated with functional improvement after surgery in 8 of 10 kidneys whereas normal values were associated with no loss of renal function on subsequent evaluation (34). In summary, the tissue tracer transit parameter may assist in the evaluation of a patient with suspected obstruction. As described previously $(33,34)$, this parameter is derived from visual inspection of the images; a more formal analysis of transit might have been useful for comparison but was not obtained in this study. Although a variety of sophisticated techniques have been developed to measure renal transit parameters and are thoughtfully described in a recent review, they have not been shown to be superior to simpler indices in the evaluation of obstruction or renovascular hypertension (35).

False-Positive and Indeterminate Studies. Despite optimal technique, a certain number of studies $(\sim 10 \%-15 \%)$ will be difficult to interpret because of an intermediate diuretic response. From a clinical point of view, it is important to decrease the number of tests that are nondiagnostic and to recognize the conditions other than obstruction that may lead to an abnormal diuretic response. Equivocal or false-positive results can occur because of the use of ${ }^{99 \mathrm{~m}} \mathrm{Tc}-$ DTPA, a distended bladder, the failure of a poorly functioning kidney to respond to furosemide, or slow washout of the radiopharmaceutical due to the reservoir effect of a grossly dilated collecting system $(2,4,5,22,24)$. False-positive and indeterminate studies may be reduced by visual or quantitative analysis of postvoid renal images.
Structured Reporting for Diuresis Renography. Reporting into a predefined structured format organizes and may fundamentally alter the way interpreting physicians think about the case as they produce the report. For diuresis renography, reporting into a predefined structure has, as a precondition, acquiring the elements required by that structured format. Adopting the structured format and acquiring into structure provide a means for physicians to ensure that diuresis renography studies performed in their departments contain the essential elements required for the study to be evaluated and interpreted; reporting into structure guides the assembly of the essential elements required for an informed conclusion to be reached. Information acquired in a consistent format has the additional advantage of easy retrieval and can be broadly analyzed to support medical research and quality improvement. Finally, the structured format provides a means for outside observers to assess the quality of the study and document procedural competency; the essential acquisition parameters and quantitative measurements either are present or are not present.

To assist clinicians, the International Scientific Committee of Radionuclides in Nephrology has developed a structured-report guidance document for diuresis renography that categorizes the elements of the procedure and clinical history as essential (must be included in the report), recommended, local option (possibly useful but lacking sufficient data to justify a stronger ranking), and not necessary (does not contribute to quality assurance or scan interpretation); many of these elements are discussed in this review, but a more detailed discussion of the scan elements and the rationale for the specific categories is provided in the guidance document (5).

Decision Support (Expert) Systems for Diuresis Renography. Decision support systems will have an increasing impact on the practice of medicine and are rapidly being extended to image analysis and interpretation. iRENEX is a renal expert system being developed to assist physicians in the evaluation of ${ }^{99 m}$ Tc-MAG3 renography for patients with suspected obstruction $(28,36)$. This decision support system combines clinical information with quantitative data extracted through automated image analysis to reach a conclusion about suspected obstruction and to provide the rationale for the conclusion (37). Initial data suggest that the interpretations of RENEX (automated analysis of the quantitative data derived from renogram acquisition) is indistinguishable from the interpretations of expert readers (38); moreover, pilot studies of iRENEX (RENEX plus clinical information) have shown that iRENEX performs comparably to experts with clinical information and can reduce interobserver variability among resident physicians and lead to better agreement with expert interpretations $(35,39)$. Approaches such as iRENEX have the potential to help define the essential interpretative criteria for diuresis renography, foster standardized interpretation, teach trainees to better interpret renal scans, and enhance diagnostic accuracy (40).

\section{SUSPECTED RENOVASCULAR HYPERTENSION (ANGIOTENSIN-CONVERTING ENZYME [ACE] INHIBITION RENOGRAPHY)}

Goldblatt first demonstrated the link between renal artery stenosis (RAS) and persistent hypertension in 1934. In this experimental work, he showed that hypertension could be induced by placement of a clip on the renal artery and that the hypertension would subside after the clip was removed. Although the presence of such curable hypertension has been proven in humans, the cause-and-effect relationship between RAS and hypertension is more complex than originally suspected and the diagnostic and therapeutic approaches 


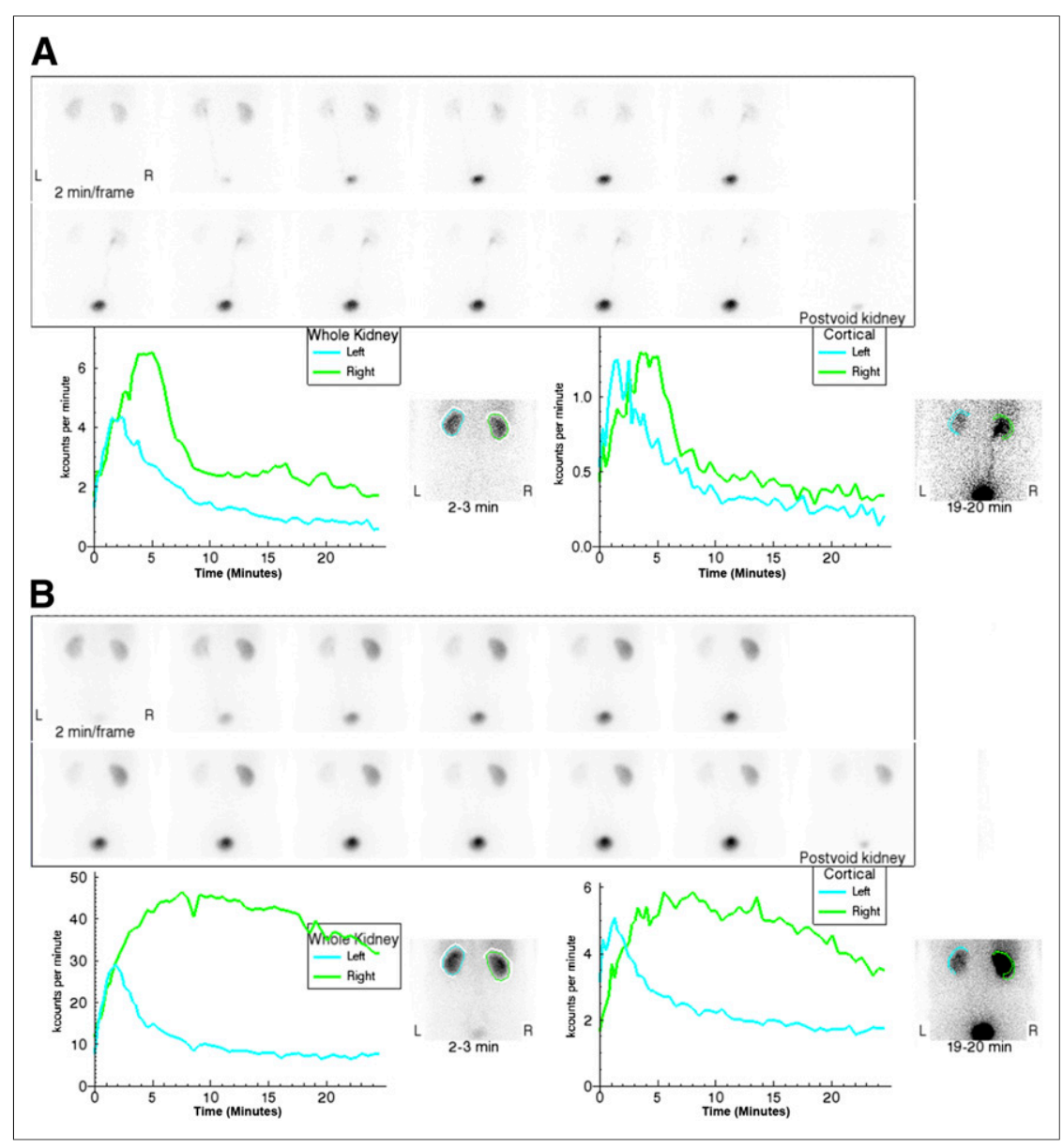

FIGURE 3. A 52-y-old hypertensive patient with normal level of serum creatinine underwent CT for possible incarcerated abdominal hernia. CT scan revealed heavily calcified right renal artery. Subsequent CT angiogram confirmed RAS, and ACE inhibition renal scan was requested to determine its functional significance. (A) Baseline scan was obtained after injection of $52 \mathrm{MBq}$ (1.4 mCi) of 99mTc-MAG3. Upper panel shows sequential 2-min 99mTc-MAG3 images. Lower left panel shows whole-kidney renogram curves (blue, left kidney; green, right kidney); lower right panel shows cortical renogram curves. Relative uptake was $51 \%$ (left) and $49 \%$ (right), with 99mTc-MAG3 clearance of $295 \mathrm{~mL} / \mathrm{min} / 1.73 \mathrm{~m}^{2}$. Images appear normal, with time to maximum counts (Tmax) and 20-min/maximum count ratios in reference range for both kidneys although there was asymmetry, with Tmax for right kidney $(4.8 \mathrm{~min}$ ) more delayed than Tmax for left kidney (1.8 $\mathrm{min}$ ); in addition, 20-min/maximum ratio for right kidney, 0.30 , was higher than that of left (0.19). (B) Patient received intravenous injection of $2.5 \mathrm{mg}$ of enalaprilat followed $20 \mathrm{~min}$ later by second $99 \mathrm{mTc}-\mathrm{MAG} 3$ injection of $333 \mathrm{MBq}(9.0 \mathrm{mCi})$. Left kidney was normal. Relative function was essentially unchanged, $49 \%$ on left and $51 \%$ on right, but sequential 2-min images showed marked parenchymal retention of tracer in right kidney, with correspondingly abnormal wholekidney and cortical renogram curves. Marked change in right kidney from baseline to ACE study indicates high probability for renovascular hypertension. (Reprinted with permission of (81).) ration of the hypertension after revascularization. Consequently, it comes as no surprise that the Scottish, EMMA (Essai Multicentrique Medicaments vs. Angioplastie), and DRASTIC (Dutch Renal Artery Stenosis Intervention Cooperative) studies and the more recent STAR (Study of Tamoxifen and Raloxifene) and ASTRAL (Angioplasty and Stenting for Renal Artery Lesions) trials show that the indiscriminate revascularization of an atherosclerotic RAS appears to have little advantage over optimal medical therapy and is no longer justified $(41,42,46,47)$. These 5 trials, however, failed to distinguish between the impact of revascularization in a hypertensive patient with an anatomic RAS and the impact of revascularization in a hypertensive patient with a functionally significant stenosis. Although indiscriminate revascularization of a stenotic renal artery in hypertensive patients appears to be no longer justified, more focused selection criteria that evaluate the functional significance of the stenosis may lead to improved outcomes. The relevant question is which hypertensive patients have a RAS that, if corrected, will lead to cure or amelioration of the hypertension.

Spiral CT angiography and MR angiography provide detailed images of the aorta and renal arteries and have high sensitivity and specificity for detecting RAS (43). A limitation of CT angiography and MR angiography, however, is the lack of information on pressure distal to the stenosis (43). In addition, CT angiography carries the risk of contrast nephrotoxicity in azotemic patients, and the use of MR contrast in patients with a low GFR is associated with nephrogenic systemic fibrosis. Doppler ultrasound is reported to provide reliable hemodynamic assessment of renal artery lesions in selected centers, but others have found it to be time-consuming, operator-dependent, lacking diagnostic uniformity, and too unreliable in obese individuals to be an efficient tool to screen hypertensive patients for a functionally significant RAS $(43,44,48)$. to the hypertensive patient with suspected RAS remain controversial $(41,42)$.

The 2 most common diseases of the renal arteries are atherosclerotic renal artery disease and fibromuscular dysplasia. Atherosclerotic renal artery disease accounts for more than $90 \%$ of the cases and is the most common cause of secondary hypertension $(43,44)$. However, atherosclerotic renal artery disease is common in the aging population, may be present in as many as $25 \%$ of normotensive patients over 50 y old (45), and is often present as an incidental or secondary finding in hypertensive patients $(41,45)$. Atherosclerotic renal artery disease is far more common than renovascular hypertension, whose classic definition is based on cure or amelio-

\section{Pathophysiology of Renovascular Hypertension and ACE Inhibition}

A functionally significant RAS results in a decrease in the perfusion pressure distal to the stenosis leading to a decrease in the transglomerular pressure gradient; the reduction in the transglomerular pressure gradient leads to a decrease in the glomerular filtrate and a decrease in sodium delivery to the distal tubule. These processes stimulate the release of renin from the juxtaglomerular apparatus. Renin cleaves angiotensin I from angiotensinogen, and angiotensin I is then converted to angiotensin II by ACE. Angiotensin II, a potent vasoconstrictor, preferentially constricts the efferent arteriole of the glomerulus, raising the transglomerular 
pressure gradient and functioning to maintain GFR even in the face of a moderate reduction in perfusion pressure.

ACE inhibitors block the conversion of angiotensin I to angiotensin II and thereby interfere with the angiotensin II-mediated constriction of the efferent arteriole; ACE inhibitors also inhibit kininase II, a dipeptidylcarboxy-peptidase that inactivates bradykinin. Bradykinin then accumulates and is a potent vasodilator causing selective efferent arteriolar dilation (49-51). This second mechanism is probably quite important since only $60 \%$ of angiotensin II is synthesized by ACE-dependent pathways in the human renal cortex and neither acute nor chronic ACE inhibition completely eliminates angiotensin II from the plasma (52).

The reduction in GFR in patients with a functionally significant RAS after ACE inhibition can be detected by a decrease in renal uptake of ${ }^{99 \mathrm{~m}} \mathrm{Tc}$-DTPA by the affected kidney compared with the baseline scan or by parenchymal retention of tubular tracers such as ${ }^{99 m}$ Tc-MAG3 (Fig. 3) secondary to the decreased flow of glomerular filtrate through the renal tubules (53-56).

\section{Performance of the Examination}

Detailed recommendations for performance of ACE inhibition renography are described in consensus reports $(57,58)$, but several points should be emphasized.

Selection of Patients for ACE Inhibition Renography. Risk factors for renovascular hypertension include abrupt or severe hypertension, hypertension resistant to medical therapy, abdominal or flank bruits, unexplained azotemia in an elderly hypertensive patient, worsening renal function during ACE inhibition therapy, grade 3 or 4 hypertensive retinopathy, a history of heavy smoking, occlusive disease in other vascular beds, and onset of hypertension under age $30 \mathrm{y}$ or over age $55 \mathrm{y}$. To determine the most appropriate test, patients need to be categorized into those with a low likelihood of renovascular hypertension, those with a moderate to high likelihood of renovascular hypertension and normal renal function, and those with a moderate to high likelihood of renovascular hypertension and azotemia.

Technologies are evolving and multiple diagnostic imaging strategies have been proposed, but to date, there is no generally accepted approach. Costs need to be considered in determining the clinical approach, but costs are a moving target and hard to ascertain. Patients with a low likelihood of renovascular hypertension can be treated medically without imaging studies. For the patient with one or more risk factors for renovascular hypertension, normal renal function, and no known unilateral kidney disease, ACE-inhibition renography provides a logical and cost-effective diagnostic approach. In this patient population, a recent analysis showed that an ACE-inhibition renogram as the first test was more cost-effective than CT or MR angiography (57).

The evaluation of a patient with azotemia or a patient known to have a small, poorly functioning kidney is more problematic. In this patient population, a positive ACE-inhibition renogram still has a high predictive value for amelioration of the hypertension with revascularization, but a large percentage of the tests may be indeterminate for renovascular hypertension, and the accuracy of the test in this population is reduced (53-55). The advantages and disadvantages of other diagnostic approaches have been described, and test selection should be based on local expertise, cost, and how the test result will influence patient management.

One-Day Versus Two-Day Protocols. The traditional approach is a 1-d protocol; a baseline acquisition is performed with approximately $40 \mathrm{MBq}$ of ${ }^{99 \mathrm{~m}} \mathrm{Tc}-\mathrm{MAG} 3$ or ${ }^{99 \mathrm{~m} T c-D T P A}$; the
ACE inhibitor is administered after the baseline acquisition and followed by a second acquisition with approximately $370 \mathrm{mBq}$ of ${ }^{99 \mathrm{~m}}$ Tc-MAG3 or ${ }^{99 \mathrm{~m}}$ Tc-DTPA, which minimizes the effect of any residual activity in the kidney from the baseline study and allows an immediate comparison between the baseline and ACE inhibition results. An alternative approach is to begin with ACE inhibition renography since normal findings have a low probability for renovascular hypertension and obviate a baseline acquisition. If the ACE inhibition findings are abnormal, the specificity can be improved by obtaining a baseline renogram; however, the patient will have to return for the baseline study on another day because of the earlier administration of the ACE inhibitor.

Choice of Radionuclide. In patients with azotemia, tubular agents such as ${ }^{99 \mathrm{~m}} \mathrm{Tc}-\mathrm{MAG} 3$ or ${ }^{123} \mathrm{I}$ are the agents of choice $(54,55)$. In patients with normal function, ${ }^{99 \mathrm{~m} T c-M A G 3}$ and ${ }^{99 m}$ Tc-DTPA appear to give comparable results $(54,55)$.

ACE Inhibitors, Angiotensin II Receptor Blockers, and the Need for an Intravenous Line. Most ACE inhibition studies have been performed with captopril (25-50 mg); the tablet should be crushed and administered with approximately $250-500 \mathrm{~mL}$ of water (54). A 25-mg tablet is sufficient unless the patient has delayed gastric emptying or poor absorption from the gastrointestinal tract. Since the presence of food in the gastrointestinal tract can reduce the absorption of captopril by $30 \%-40 \%$, patient should avoid solid food for $4 \mathrm{~h}$ before the examination (58). Peak blood levels occur approximately $60 \mathrm{~min}$ after oral administration, and for this reason, the radiopharmaceutical administration should be delayed for 60-90 min after captopril administration.

Enalaprilat (Vasotec [Merck and Co., Inc.], $40 \mu \mathrm{g} / \mathrm{kg}$ intravenously over 3-5 min, maximum dose of $2.5 \mathrm{mg}$ ) administered at least $15 \mathrm{~min}$ before tracer administration is an acceptable alternative $(54,55,59)$. Intravenous injection of enalaprilat avoids the possibility of a false-negative result due to delayed gastric emptying or poor absorption; potential disadvantages are infiltration of the dose and the possibility of a greater risk of a hypotensive response. An intravenous line is recommended for high-risk individuals and for individuals receiving enalaprilat so that normal saline can be infused if patients develop symptomatic hypotension $(54,55)$. Chronic ACE inhibition may reduce the sensitivity of the test $(54,55,60)$; for this reason, captopril should be discontinued for $4 \mathrm{~d}$ before the study and ACE inhibitors with a longer half-life should be discontinued for $7 \mathrm{~d}(54,55)$. Data are limited regarding the impact that chronic administration of angiotensin II receptor blockers may have on the sensitivity and specificity of ACE inhibition renography, but the one study suggests it may not be necessary to discontinue this class of drugs (50).

Hydration, Diuretics, and Furosemide Administration. Chronic diuretic administration increases the likelihood of volume depletion, which may lead to renal retention of the radiopharmaceutical, reduce the specificity of the test, and increase the risk of a hypotensive response. These concerns can be minimized if diuretics are discontinued for several days before the study. The likelihood of volume depletion can be further reduced if the patient is instructed to arrive well hydrated, is given approximately $500 \mathrm{~mL}$ of water on arrival in the department, and continues to receive hydration between a baseline and ACE inhibition acquisition. Some clinicians recommend the intravenous administration of furosemide $(20 \mathrm{mg})$ at the time of tracer injection to minimize the likelihood of tracer retention in the collecting system and to thereby facilitate an accurate measurement of the parenchymal 20-min/maximum count ratio (59). A recent consensus report, however, considered 


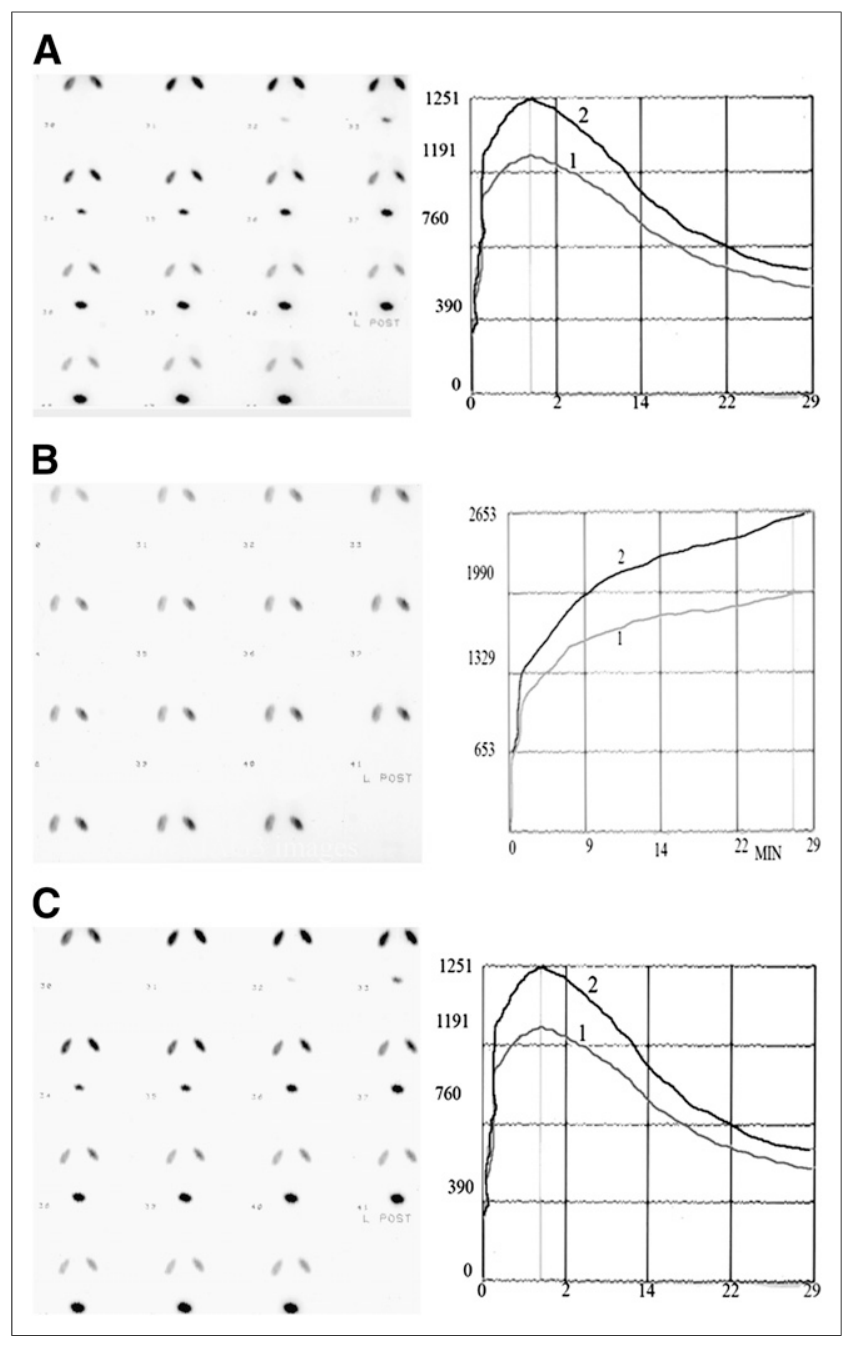

FIGURE 4. Middle-aged man with refractory hypertension was referred for ACE inhibition renography. (A) Sequential 2-min images and whole-kidney renogram curves were obtained after baseline injection of approximately $37 \mathrm{MBq}(1.0 \mathrm{mCi})$ of ${ }^{99 \mathrm{mTc}} \mathrm{T}-\mathrm{MAG} 3$. (B) Patient received 50 $\mathrm{mg}$ of captopril, and $370 \mathrm{MBq}(10 \mathrm{mCi})$ of ${ }^{99 \mathrm{mTc}-M A G 3}$ were injected 1 $\mathrm{h}$ later. Two-minute images demonstrated parenchymal retention, with bilateral rising whole-kidney renogram curves. Usually, renovascular hypertension produces asymmetric abnormalities. Further review showed that patient's precaptopril blood pressure had been $165 / 71$ but fell to $102 / 41$ during the study, even though patient remained asymptomatic. (C) Several days later, study was repeated with $50 \mathrm{mg}$ of captopril and intravenous hydration to maintain blood pressure. (D) Two-minute sequential images and renogram curves were normal. Bilateral symmetric abnormalities after ACE inhibition are a nonspecific finding and are often due to volume depletion and hypotension. (Reprinted with permission of (82).

the administration of furosemide unnecessary if the patient is well hydrated and parenchymal ROIs are well defined (54,55). A urine flow rate of less than $1-2 \mathrm{~mL} / \mathrm{min}$ during the baseline acquisition may suggest the need for additional hydration or furosemide administration; if furosemide is administered with an ACE inhibitor, an intravenous line is recommended in case the patient develops symptomatic hypotension $(54,55)$.

Blood Pressure Monitoring. Asymptomatic hypotension secondary to ACE inhibition can result in bilateral symmetric abnormalities in the renogram curves (Fig. 4) $(57,61,62)$. This phenomenon is relatively uncommon but may occur in as many

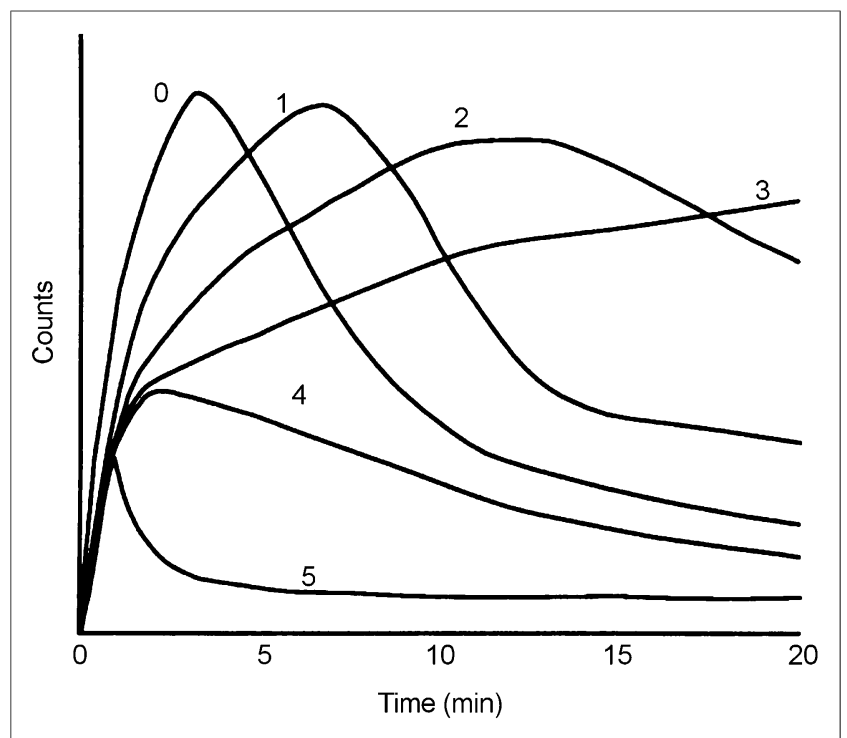

FIGURE 5. Common renogram patterns used for visual interpretation of ACE inhibition renography: type 0 , normal; type 1 , time to peak (Tmax) of $>5 \mathrm{~min}$ and 20-min/maximum count ratio of $>0.3$ for background-subtracted ${ }^{131}$-orthoiodohippurate and 99mTc-MAG3 curves; type 2, more exaggerated delays in time to peak and in parenchymal washout; type 3 , progressive parenchymal accumulation (no washout detected); type 4, renal failure pattern but with measurable renal uptake; type 5 , renal failure pattern representing blood background activity only.

as $3 \%$ of patients referred for ACE inhibition renography, usually in patients who are volume- or salt-depleted $(61,62)$.

\section{Diagnostic Criteria}

Consensus panels have recommended that the test be interpreted as high, low, or intermediate (indeterminate) probability for renovascular hypertension $(54,55)$. A high-probability test shows unilateral deterioration of the renogram curve or a change in relative function after ACE inhibition compared with the baseline study. An intermediate-probably test shows a kidney that is small and poorly functioning or kidneys with abnormal baseline renograms (grades III-V) that are unchanged after ACE inhibition. A low-probability test shows a normal ACE inhibition renogram or a grade II renogram that is unchanged or improves after ACE inhibition.

A change in the shape of the renogram curve may be evaluated qualitatively (Fig. 5) or quantitatively by a prolongation of the 20or $30-\mathrm{min} / \mathrm{maximum}$ ratio or a prolongation of the time to peak. For tubular tracers, a unilateral increase in the 20-min/maximum ratio of 0.15 or greater (e.g., $0.30-0.45$ or higher) for parenchymal ROIs represents the $90 \%$ confidence limit for a significant change (53-55). A prolongation of the time to peak of $120 \mathrm{~s}$ for a parenchymal ROI is significant at the $90 \%-95 \%$ confidence limit. It is important to note, however, that a change from 5 to $7 \mathrm{~min}$ is much more meaningful than a change from 15 to $17 \mathrm{~min}$. Renograms derived from the cortical ROIs can minimize the error or diagnostic difficulty that can be introduced by retention of the tracer in the collecting system; however, cortical renogram curves from kidneys with markedly reduced function may be too noisy to give reliable results. A change in the relative uptake of ${ }^{99 m}$ Tc-MAG3 or ${ }^{131}$ I-orthoiodohippurate by $10 \%$ (50/50 to $40 / 60$ ) is uncommon even in a patient with renovascular hypertension but is highly significant when it occurs.

The principal diagnostic criterion for ${ }^{99 \mathrm{~m}} \mathrm{Tc}-\mathrm{DTPA}$ is a change in the relative uptake. A reduction in the relative uptake greater than $10 \%$ 
(50/50 to 60/40) is a highly significant change and $5 \%-9 \%$ is considered to be an intermediate response $(54,55)$, although one study performed under carefully controlled conditions suggested that smaller changes in relative uptake may be significant (53). Parenchymal retention of ${ }^{99 \mathrm{~m}} \mathrm{Tc}-\mathrm{DTPA}$ with a prolongation of the renogram curve after ACE inhibition can also be an important diagnostic finding and can be quantitated by a delay in the time to peak or an increase in the 20- to 30-min/maximum ratios. In general, however, because of the lower extraction fraction of ${ }^{99 \mathrm{~m}} \mathrm{Tc}-\mathrm{DTPA}$ than of ${ }^{99 \mathrm{~m}} \mathrm{Tc}-\mathrm{MAG} 3$, changes in the renogram curve are more subtle and a change in relative uptake is a more reliable diagnostic criterion $(54,55)$.

\section{Sensitivity and Specificity of ACE Inhibition Renography}

ACE inhibition renography in an appropriately screened hypertensive patient with preserved renal function can detect renovascular hypertension with a sensitivity approximating $90 \%(50,53,57,59$, 63-71). Using the criterion of ACE inhibition-induced changes between baseline and ACE inhibition scans to define a positive test, the test has a specificity of at least $90 \%$ and consequently has a high positive predictive value $(57,68)$. The sensitivity and specificity of ACE inhibition renography, however, are affected by several factors that have contributed to confusion in the literature.

Use of Anatomic Presence of RAS as Surrogate for Renovascular Hypertension. ACE inhibition renography is a test to detect a functionally significant RAS; it is not a test to detect the presence of an anatomic RAS $(54,55)$. Nevertheless, many investigators have used the angiographic presence of a stenosis greater than $50 \%$ as a surrogate for renovascular hypertension despite the fact that many of these stenotic lesions will not be hemodynamically significant $(55,57,68,72-74)$. In an attempt to circumvent this problem, other investigators have used the more stringent standard of a stenosis greater than $70 \%$. Although good results have been reported using RAS as the gold standard (70), not surprisingly, the sensitivity and specificity of ACE inhibition renography is improved when the gold standard is the response to revascularization rather than the anatomic presence of RAS (50,65-69).

Patient Selection: Test Performance in Azotemic and Nonazotemic Populations. Some studies have reported good results in azotemic patients $(59,71)$, but one study reported that almost $50 \%$ of tests in this population were of intermediate probability and nondiagnostic (53). ACE inhibition renography is probably less accurate in the azotemic population, although a positive test in an azotemic patient indicates a high likelihood that the hypertension will be ameliorated by revascularization $(53-55,63)$. It is important to be certain that the referring physician distinguishes between the utility of the test in azotemic and nonazotemic populations to avoid unrealistic expectations. The test is reliable in the nonazotemic patient with relatively good bilateral function, but ACE inhibition renography is often nondiagnostic in the azotemic patient or the patient with a small, poorly functioning kidney and may have reduced accuracy.

Analysis of Intermediate-Probability, or Indeterminate, Scan. To calculate sensitivity and specificity, indeterminate results must be placed with the high- or low-probability results. Intermediateprobability studies placed in the high-probability category increase sensitivity at the expense of specificity, and conversely, intermediate-probability studies placed in the low-probability category increase specificity at the expense of sensitivity (50). The reported values for sensitivity and specificity vary depending on the prevalence of azotemic patients in the study population and how intermediate probability results are handled in the data analysis.
Inconsistent Use of Recommended Interpretation Criteria for ACE Inhibition Renography. Interpretative criteria for ACE inhibition renography were published in 1996 as an international consensus report; this report has subsequently been updated by the Society of Nuclear Medicine and Molecular Imaging, published on its website $(54,55)$. Strict adherence to these criteria improves the performance of ACE inhibition renography (75), and subsequent studies should include an analysis based on these criteria.

\section{RENAL TRANSPLANT SCINTIGRAPHY}

\section{Donor Evaluation}

Renal scintigraphy can evaluate global and individual renal function in potential donors, as well as help determine which kidney to select for donation. Use of renal scintigraphy in donor evaluation, however, varies widely between centers.

\section{Transplant Evaluation}

Complications of renal transplantation can be divided into parenchymal failure (acute tubular necrosis, acute and chronic rejection, and calcineurin inhibitor toxicity) and mechanical failure (injury to the renal artery or vein, ureteral obstruction, and urine leak). Sonography is usually the first approach for evaluation of renal graft dysfunction, but a renal scan can provide complementary information. A normal scan result immediately after transplantation excludes mechanical complications. Serial scans during the first 1-3 wk after transplantation may detect early rejection 24-48 h before biochemical abnormalities occur and can be used to monitor recovery from posttransplantation acute tubular necrosis. Classically, acute tubular necrosis presents with relatively preserved perfusion accompanied by delayed uptake and excretion, although severe acute tubular necrosis can also present with diminished flow. Rejection presents as diminished flow with delayed uptake and excretion.

Chronic transplant nephropathy represents cumulative and incremental damage to nephrons from both immunologic and nonimmunologic causes. Imaging studies are obtained if the clinician suspects complications relating to renal blood flow, urine leak, urinoma, obstruction, abscess, hematoma, or lymphoma. Sonography is typically the first approach. A renal scan may provide complementary information regarding obstruction or a urine leak, and ACE inhibition renography can detect renovascular hypertension (76); however, a renal scan cannot reliably distinguish between rejection and calcineurin-inhibitor nephrotoxicity.

\section{RENAL CORTICAL SCINTIGRAPHY (PYELONEPHRITIS AND SCAR)}

Pyelonephritis is a serious illness in the pediatric population; renal scarring from recurring infection remains an important cause of substantial long-term morbidity $(76,77)$. Clinical and experimental studies have demonstrated that scarring can be prevented or diminished by early diagnosis and aggressive therapy. In infants and young children, pyelonephritis is not always accompanied by high fever, an elevated sedimentation rate, and leukocytosis. Furthermore, a normal voiding cystourethrogram does not exclude acute pyelonephritis, and it is increasingly recognized that sonography and excretory urography cannot be used to exclude acute pyelonephritis in infants and children. Renal cortical ${ }^{99 \mathrm{~m}}$ Tc-dimercaptosuccinic acid (DMSA) scintigraphy is more sensitive for the detection of pyelonephritis than sonography. MR imaging and contrast-enhanced CT are also sensitive tests for the detection of 
pyelonephritis, but MR imaging is expensive, and there is the possibility of an allergic reaction to iodinated contrast material given during the CT scan.

${ }^{99 m}$ Tc-DMSA is the radiopharmaceutical of choice for imaging the renal cortex (78-80). Static images are obtained 2-4 h after injection, and sedation is rarely needed. A normal scan demonstrates a homogeneous concentration of the radiotracer throughout the kidney except for a lower concentration in the region of the collecting system. ${ }^{99 \mathrm{~m} T c-D M S A}$ scans can measure relative function and identify functioning renal tissue in patients with congenital abnormalities. In patients who have a nonstandard anatomic location of the kidneys, such as anterior displacement and ptosis, an anterior and posterior acquisition with geometric mean calculation will yield a more reliable measurement of relative function. ${ }^{99 m}$ Tc-DMSA scans are most commonly obtained in patients with suspected pyelonephritis to distinguish upper from lower urinary tract infections and to detect the presence of scarring after an episode of acute pyelonephritis. Pyelonephritis and scarring are recognized by focal areas of decreased ${ }^{99 m}$ Tc-DMSA uptake in the renal parenchyma; however, a focal abnormality is not specific for pyelonephritis or a renal scar since any process that replaces, injures, or destroys normal cortical parenchyma will result in an abnormal scan.

Some institutions treat pediatric patients with suspected pyelonephritis empirically and pursue diagnostic studies only if the patient does not respond to antibiotic therapy. In other institutions, patients with pyelonephritis receive more aggressive therapy or follow-up in the hope of reducing the risk of scarring and recurrent infection and, thereby, avoiding the subsequent development of hypertension and renal cortex failure (67,77-80). At present, there is no consensus on the use of ${ }^{99 \mathrm{~m}} \mathrm{Tc}-\mathrm{DMSA}$ scans in the evaluation and follow-up of patients with urinary tract infection. The diagnostic approach depends on whether a positive or negative ${ }^{99 \mathrm{~m}} \mathrm{Tc}-$ DMSA scan will alter patient management.

\section{POTENTIAL PITFALLS}

Potential pitfalls have been described throughout parts 1 and 2 of this review. Several of these potential pitfalls are summarized below and further highlighted in the SAM questions.

Inadequate hydration can result in parenchymal retention, asymmetric retention in a renal pelvis, and an abnormal renogram response after ACE inhibition; the level of hydration and response to furosemide can be evaluated by measuring the voided volume or urine flow rate as described in part 1 . Diclofenac, a nonsteroidal antiinflammatory drug, blocks the production of prostaglandins and has been shown to inhibit spontaneous ureteric contraction, prolong the transit time, and delay the time to peak height of the renogram curve of ${ }^{99 \mathrm{~m}} \mathrm{Tc}-\mathrm{MAG} 3$ in healthy individuals and can lead to a false-positive study. Failure to have the patient void immediately before the study may result in an uncomfortably full bladder requiring the patient to terminate the study prematurely. Dose infiltration will result in errors in the camera-based measurements of clearance and can lead to bilaterally abnormal renogram curves due to continued absorption of the infiltrated dose.

Use of ${ }^{99 \mathrm{~m}} \mathrm{Tc}$-DTPA for diuretic renography may result in an equivocal or false-positive diuretic study compared with ${ }^{99 \mathrm{~m}} \mathrm{Tc}$ MAG3, particularly in patients with reduced function. Use of a whole-kidney ROI to evaluate drainage may lead to an abnormally prolonged $T^{1} / 2$ when the kidney has reduced function with parenchymal retention; an ROI placed over the retained tracer provides a more reliable measure of washout. Use of the whole-kidney ROI to evaluate time to peak, or Tmax, and the $20-\mathrm{min} /$ maximum ratio may give misleading values for parenchymal function due to physiologic and possibly asymmetric retention of the tracer in one of the collecting systems; the cortical (parenchymal) ROI provides a more robust measurement but may give misleading results in patients with poor renal function because of the statistical noise of reduced counts in the parenchymal ROI. Failure to evaluate drainage based on a postvoid image of the kidney can result in a falsepositive or equivocal interpretation when the patient does not have an obstructed kidney. The $\mathrm{F}-15$ or $\mathrm{F}=0$ protocol may demonstrate rising parenchymal activity without visualization of tracer in the collecting system in a nonobstructed but poorly functioning kidney, leading to an incorrect interpretation of indeterminate or obstructed kidney, whereas an $\mathrm{F}+20$ protocol or a protocol that allows visualization of tracer in the collecting system and then documents appropriate washout would lead to a correct interpretation of poor function in the absence of obstruction.

An inferior background ROI undercorrects background for both ${ }^{99 m}$ Tc-MAG3 and DTPA studies and can introduce errors in calculating relative renal function; a perirenal background normalized to the kidney ROI is preferred over background regions placed inferior to the kidney. Automated background assignments that track the kidney ROI reduce processing time and enhance reproducibility; however, a perirenal background that includes retained tracer in the renal pelvis may result in oversubtraction of background during the latter portion of the renogram curve, leading to errors in the calculation of the 20 -min/maximum count ratios. Patients with severely reduced renal function will have relatively low kidney-to-background ratios, and the measurement of relative uptake in the 1- to 3-min postinjection period as provided in most commercial software may lead to erroneous values. Relative function is typically measured in the 1- to 2- or 1- to 3-min period after injection because the measurement needs to be made before any tracer leaves either kidney. If the bladder is not visualized until later in the study, for example, at 15 min after injection, calculating the relative uptake at 13-14 min will provide a more reliable measurement since there will have been additional time for the kidney to accumulate the tracer and for the background to diminish.

Failure to inform the referring physician that ACE inhibition renography may yield a nondiagnostic study in up to $50 \%$ of patients with azotemia or a small, poorly functioning kidney may lead the referring physician to have unrealistic expectations for the test. If blood pressure fails to be monitored during the study, an episode of clinically inapparent hypotension that leads to an abnormal renogram may be missed.

Measurement of residual urine volume is a simple and often useful adjunct to the renal scan and can be based on the counts in pre- and postvoid ROIs over the bladder and a measurement of the voided volume. To maintain a consistent geometry, pre- and postvoid images should be obtained with the patient in the same position. The main source of error is tracer in the renal pelvis that drains into the bladder after the patient voids and before the postvoid image is obtained. The likelihood of this error can be minimized if patients can walk around for a couple of minutes to facilitate and complete gravity-assisted drainage before the prevoid and postvoid bladder images. These potential sources of error are summarized in Table 1.

\section{AREAS FOR FUTURE RESEARCH}

\section{Visual or Quantitative Evaluation of Renal Flow}

Renal scans are frequently performed after the intravenous injection of approximately $370 \mathrm{MBq}(10 \mathrm{mCi})$ of ${ }^{99 \mathrm{~m}} \mathrm{Tc}-\mathrm{MAG} 3$ or 


\begin{tabular}{|c|c|}
\hline Pitfall & Discussed in... \\
\hline Inadequate hydration & Part 1 of article \\
\hline Delayed ureteral transit caused by diclofenac & Part 1 of article \\
\hline Failure to have patient void before study & Part 1 of article \\
\hline Dose infiltration & Part 1 of article \\
\hline Error in recording patient's height, weight, or dose injected & Part 1 of article \\
\hline Patient motion resulting in spurious quantitative indices & Part 1 of article \\
\hline Failure to use urinary drainage catheter for patients with urinary diversions & Part 2 of article \\
\hline Insufficient dose of furosemide to obtain adequate diuresis in kidney with reduced function & Part 2 of article \\
\hline Failure to obtain postvoid kidney image to evaluate drainage & Part 2 of article \\
\hline Use of whole-kidney $\mathrm{ROI}$ to evaluate washout rather than $\mathrm{ROI}$ limited to dilated collecting system & Part 2 of article \\
\hline $\begin{array}{l}\text { Use of parenchymal ROI reference values as standard for whole-kidney ROI measurements of } \mathrm{T}^{1} 1 / 2 \\
\text { or } 20-\mathrm{min} / \text { maximum count ratio }\end{array}$ & Part 2 of article \\
\hline $\begin{array}{l}\text { Measurement of relative function during } 1 \text { - to } 3 \text {-min postinjection period in patients with severely } \\
\text { impaired renal function and delayed urine excretion }\end{array}$ & Part 2 of article \\
\hline
\end{tabular}

${ }^{99 m}$ Tc-DTPA. Administration of activities in the range of 370 $\mathrm{MBq}$ may be required to obtain sufficient counts to visualize the initial bolus as it transits the aorta and kidneys or to calculate quantitative flow indices; however, except for the evaluation of renal transplants, neither 2-s flow images nor quantitative flow calculations obtained in the first few seconds after injection have been demonstrated to be superior to simpler measurements in the evaluation of relative function, suspected obstruction, or renovascular hypertension. An administered dose of $370 \mathrm{MBq}$ is unnecessarily high for almost all applications, and a range from 37 to $185 \mathrm{MBq}$ is much more appropriate $(2,5)$.

\section{Suspected Obstruction}

Pilot studies have shown that diuresis renography performed in the emergency room can have a substantial impact on the management of patients presenting with renal colic and a ureteral calculus documented by unenhanced CT $(11,12,26,27)$. Additional studies are needed to confirm these initial results and evaluate both cost-effectiveness and the impact of diuretic renography on patient management and outcome.

Preliminary studies suggest that tissue tracer transit can help differentiate between kidneys at risk for losing function and those not requiring intervention to preserve function $(33,34)$; additional studies are needed to evaluate the utility of this and other diagnostic parameters in predicting patient outcome.

To achieve an appropriate diuretic response, patients with chronic renal insufficiency require serum concentrations of furosemide high enough to provide entry of sufficient amounts of diuretic into the renal tubular fluid $(19,20)$. When one kidney has impaired function but overall renal function is normal, there is the possibility that a 40-mg dose of furosemide will result in an indeterminate or false-positive result due to an inadequate diuretic response in the compromised kidney. This possibility needs further investigation.

Initial data indicate that decision support systems for diuretic renography have the capacity to identify essential elements, facilitate training of students and residents, encourage standardization of procedures, populate structured reports, and assist in study interpretation $(23,28,37-$ 40). These initial results need broader development and evaluation.

\section{Suspected Renovascular Hypertension}

Randomized trials have shown little benefit from the unselected revascularization of stenotic renal arteries in hypertensive patients
(50-54); however, these results should not be overgeneralized, and additional studies are needed that focus on revascularization of the subset of patients with atherosclerotic renovascular disease who have a functionally significant stenosis documented by ACE inhibition renography.

Additional studies are needed to better define the utility of ACE inhibition renography in predicting response to revascularization in patients with varying degrees of azotemia.

\section{Renal Donor and Transplant Evaluation}

Renal scintigraphy can evaluate flow to the transplant as well as transplant function and drainage, and serial scans can assist in detecting early rejection; nevertheless, the incremental value of renal scintigraphy and its use as a cost-effective modality in the evaluation of the renal-transplant donor and recipient compared with other diagnostic approaches is poorly defined. Centers that currently have a large volume of renal scintigraphy studies evaluating the renal donor and renal transplant need to conduct carefully designed cost-benefit studies to clarify the role of renal scintigraphy in the management of potential donors and the recipient.

\section{CONCLUSION}

Radionuclide renography can be a complex subject since several radiopharmaceuticals are available to image the kidney and monitor renal function; multiple quantitative indices can be generated, and protocols vary depending on institutional preference and clinical setting. Part 1 of this review focused on the advantages and limitations of available radiopharmaceuticals, the quality control elements needed to optimize the study, and measurement of common quantitative indices designed to assist in scan interpretation. Part 2 has used the information presented in part 1 to focus on specific diagnostic applications, including suspected obstruction and renovascular hypertension. Potential pitfalls were included in both part 1 and part 2 and in a series of SAM questions designed to supplement and highlight important procedural elements and aspects of scan interpretation.

\section{REFERENCES}

1. Taylor A, Lallone R. Differential renal function in unilateral renal injury: possible effects of radiopharmaceutical choice. J Nucl Med. 1985;26:77-80.

2. O'Reilly P, Aurell M, Britton K, et al. Consensus on diuresis renography for investigating the dilated upper urinary tract. J Nucl Med. 1996;37:1872-1876.

3. Gordon I, Colarinha P, Fettich J, et al. Guidelines for standard and diuretic renography in children. Eur J Nucl Med. 2001;28:BP21-BP30. 
4. Shulkin BL, Mandell GA, Cooper JA, et al. Procedure guideline for diuretic renography in children 3.0. J Nucl Med Technol. 2008;36:162-168.

5. Taylor AT, Blaufox MD, De Palma D, et al. Guidance document for structured reporting of diuresis renography. Semin Nucl Med. 2012;42:41-48.

6. Liu Y, Ghesani NV, Skurnick JH, Zukier LS. The F +0 protocol for diuretic renography results in fewer interrupted studies due to voiding than the $\mathrm{F} 15$ protocol. J Nucl Med. 2005;46:1317-1320.

7. Kuyvenhoven J, Piepsz M, Ham H. When could the administration of furosemide be avoided? Clin Nucl Med. 2003;28:732-737.

8. Adeyoju AA, Burke D, Atkinson C, et al. The choice of timing for diuresis renography for the assessment of equivocal pelviureteric obstruction. BJU Int. 2001;88:1-5.

9. Russell CD, Young D, Billingsley JD, Dubovsky EV. Technical procedures for the use of the new kidney agent technetium-99m MAG3. J Nucl Med Technol. 1991;19:147-152.

10. Wong DC, Rossleigh MA, Farnsworth RH. Diuretic renography with the addition of quantitative gravity-assisted drainage in infants and children. J Nucl Med. 2000;41:1030-1036.

11. Sfakianakis GN, Cohen DJ, Braunstein RH, et al. MAG3-F0 scintigraphy in decision making for emergency intervention in renal colic after helical CT positive for a urolith. J Nucl Med. 2000;41:1813-1822.

12. Sfakianaki E, Sfakianakis GN, Georgiou M, Hsiao B. Renal scintigraphy in the acute care setting. Semin Nucl Med. 2013;43:114-128.

13. Upsdell SM, Testa HJ, Lawson RS. The F-15 diuresis renogram in suspected obstruction of the upper urinary tract. Br J Urol. 1992;69:126-131.

14. Upsdell SM, Leeson SM, Brooman PJC, O'Reilly PH. Diruetic-induced urinary flow rates at varying clearances and their relevance to the performance and interpretation of diuresis renography. Br J Urol. 1988;61:14-18.

15. Kass EJ, Majd M. Evaluation and management of upper urinary tract obstruction in infancy and children. Urol Clin North Am. 1985;12:133-141.

16. Tartaglione G, D'Addessi A, De Waure C, et al. ${ }^{99 \mathrm{~m}}$ Tc-MAG diuretic renography in diagnosis of obstructive nephropathy in adults: a comparison between F-15 and a new procedure F+10(sp) in seated position. Clin Nucl Med. 2013;38:432-436.

17. Homsy YL, Mehta PH, Huot D, Danais S. Intermittent hydronephrosis: a diagnostic challenge. J Urol. 1988;140:1222-1226.

18. Brown SCW, Upsdell SM, O'Reilly PH. The importance of renal function in the interpretation of diuresis renography. Br J Urol. 1992;69:121-125.

19. Brater DC. Diuretic therapy. N Engl J Med. 1998;339:387-395.

20. Hunsche A, Press H, Taylor A. Increasing the dose of furosemide in patients with azotemia and suspected obstruction. Clin Nucl Med. 2004;29:149-153.

21. Voelker JR, Cartwright-Brown D, Anderson S, et al. Comparison of loop diuretics in patients with chronic renal insufficiency. Kidney Int. 1987;32:572-578.

22. Kletter K, Nürnberger N. Diagnostic potential of diuresis renography: limitations by the severity of hydronephrosis and by impairment of renal function. Nucl Med Commun. 1989;10:51-61.

23. Bao J, Manatunga A, Binongo JNG, Taylor AT. Key variables for interpreting MAG3 diuretic scans: development and validation of a predictive model. AJR. 2011;325-333.

24. Connolly LP, Zurakowski D, Peters CA, et al. Variability of diuresis renography interpretation due to method of post-diuretic renal pelvic clearance half-time determination. J Urol. 2000;164:467-471.

25. La Fata V, Ramachandran A, Galt J, Keane TE, Halkar R. Diuretic renogram in a patient with a urinary diversion: avoiding a false-positive diagnosis of obstruction with an indwelling catheter. Clin Nucl Med. 2001;26:631-632.

26. Lorberboym M, Kapustin Z, Elias S, et al. The role of renal scintigraphy and unenhanced helical computerized tomography in patients with ureterolithiasis. Eur J Nucl Med. 2000;27:441-446.

27. Orange DT Jr, Young S, Sfakianaki E, Sfakianakis GN. The effect of MAG3-F0 diuretic renography on stratification of ER patients with renal colic and a positive helical CT for admission or discharge with outpatient followup [abstract]. J Nucl Med. 2002;43(suppl):40P.

28. Garcia EV, Taylor A, Folks R, et al. iRENEX: a clinically-informed decision support system for the interpretation of Tc-99m MAG3 scans to detect renal obstruction. Eur J Nucl Med Mol Imaging. 2012;39:1483-1491.

29. Frokier J, Eskild-Jensen A, Dissing T. Antenatally detected hydronephrosis: the nuclear medicine techniques. In: Prigent A, Piepsz A, eds. Functional Imaging in Nephrourology. New York, NY: Taylor and Francis; 2006:103-115.

30. Piepsz A, Kuyvenhoven JD, Tondeur M, Ham H. Normalized residual activity: usual values and robustness of the method. J Nucl Med. 2002;43:33-38.

31. Piepsz A, Tondeur M, Ham H. NORA: a simple and reliable parameter for estimating renal output with or without frusemide challenge. Nucl Med Commun. 2000;21:317-323

32. Chaiwatanarat T, Padhy AK, Bomanji JB, Nimmon CC, Sonmezoglu K, Britton KE. Validation of renal output efficiency as an objective quantitative parameter in the evaluation of upper urinary tract obstruction. J Nucl Med. 1993;34:845-848.
33. Schlotmann A, Clorius JH, Clorius SN. Diuretic renography in hydronephrosis; renal tissue tracer transit predicts functional course and thereby need for surgery. Eur J Nucl Med Mol Imaging. 2009;36:1665-1673.

34. Schlotmann A, Clorius JH, Rohrschneider WK, Clorius SN, Amelung F, Becker K. Diuretic renography in hydronephrosis: delayed tissue tracer transit accompanies both functional decline and tissue reorganization. J Nucl Med. 2008;49:1196-1203.

35. Durand E, Blaufox MD, Britton KE, et al. International Scientific Committee of Radionuclides in Nephrology (ISCORN) consensus on renal transit time measurements. Semin Nucl Med. 2008;38:82-102.

36. Taylor A, Garcia EV, Binongo JNG, et al. Diagnostic performance of an expert system for interpretation of Tc-99m MAG3 scans in suspected obstruction. $\mathrm{J}$ Nucl Med. 2008;49:216-224.

37. Garcia EV, Taylor A, Manatunga D, Folks R. A software engine to justify the conclusions of an expert system for detecting renal obstruction on ${ }^{99 \mathrm{~m}} \mathrm{Tc}-\mathrm{MAG} 3$ scans. J Nucl Med. 2007;48:463-470.

38. Manatunga A, Binongo JNG, Taylor AT. Computer-aided diagnosis of renal obstruction: utility of log-linear modeling versus standard ROC and kappa analysis. EJNMMI Research. 2011;1:1-8.

39. Taylor AT, Shenvi NV, Folks R, et al. Tc-99m MAG3 diuretic renography: impact of a decision support system (iRENEX) on resident interpretations [abstract]. J Nucl Med. 2013;54(suppl):171P.

40. Taylor AT, Garcia EV. Computer-assisted diagnosis in renal nuclear medicine: rationale, methodology, and interpretative criteria for diuretic renography. Semin Nucl Med. 2014;44:146-158.

41. Safian RD, Madder RD. Refining the approach to renal artery revascularization. JACC Cardiovasc Interv. 2009;2:161-174.

42. de Leeuw PW, Postma CT, Kroon AA. Treatment of atherosclerotic renal artery stenosis: time for a new approach. JAMA. 2013;309:663-664.

43. Baumgartner I, Lerman LO. Renovascular hypertension: screening and modern management. Eur Heart J. 2011;32:1590-1598.

44. Dawson DL. Noninvasive assessment of renal artery stenosis. Semin Vasc Surg. 1996;9:172-181.

45. Holley KE, Hunt JC, Brown AL Jr, et al. Renal artery stenosis: a clinical-pathologic study in normotensive and hypertensive patients. Am J Med. 1964;37:14-22.

46. Bax L, Woittiez A-JJ, Kouwenberg HJ, et al. Stent placement in patients with atherosclerotic renal artery stenosis and impaired renal function. Ann Intern Med. 2009; 150:840-848.

47. Wheatley K, Ives N, Gray R, et al. Revascularization versus medical therapy for renal-artery stenosis. N Engl J Med. 2009;361:1953-1962.

48. Rocha-Singh K, Jaff MR, Kelley EL. Renal artery stenting with noninvasive duplex ultrasound follow-up: 3 year results from the RENAISSANCE renal stent trial. Catheter Cardiovasc Interv. 2008;72:853-862.

49. Gainer JV, Morrow JD, Loveland A, King DJ, Brown NJ. Effect of bradykininreceptor blockade on the response to angiotensin-converting-enzyme inhibitor in normotensive and hypertensive subjects. N Engl J Med. 1998;339:1285-1292.

50. Karanikas G, Becherer A, Wiesner K, Dudczak R, Kletter K. ACE inhibition is superior to angiotensin receptor blockade for renography in renal artery stenosis. Eur J Nucl Med Mol Imaging. 2002;29:312-318.

51. Kon V, Fogo A, Ichikawa I. Bradykinin causes selective efferent arteriolar dilation during angiotensin I converting enzyme inhibition. Kidney Int. 1993;44:545-550.

52. Sandberg K, Hong J. Kidney angiotensin receptors and their role in renal pathophysiology. Semin Nephrol. 2000;20:402-416.

53. Blaufox MD, Fine EJ, Heller S, et al. Prospective study of simultaneous orthoiodohippurate and diethylenetriaminepentaacetic acid captopril renography. J Nucl Med. 1998;39:522-528.

54. Taylor A, Nally J, Aurell M, et al. Consensus report on ACE inhibitor renography for detecting renovascular hypertension. J Nucl Med. 1996;37:1876-1882.

55. Taylor A, Blaufox MD, Dubovsky EV, et al. Society of Nuclear Medicine procedure guideline for diagnosis of renovascular hypertension. Society of Nuclear Medicine and Molecular Imaging website. http://interactive.snm.org/ docs/pg_ch16_0403.pdf. Published August 2003. Accessed February 10, 2014.

56. Visscher CA, de Zeeuw D, de Jong PE, et al. Angiotensin-converting enzyme inhibition-induced changes in hippurate renography and renal function in renovascular hypertension. J Nucl Med. 1996;37:482-488.

57. Taylor A. ACE inhibition renography in the evaluation of suspected renovascular hypertension. In Prigent A, Piepsz A, eds. Functional Imaging in Nephro-Urology. Abingdon, Oxon, U.K.: Taylor and Francis; 2006:149-164.

58. Physicians Desk Reference. $61^{\text {st }}$ ed. New York, NY: Thomson Reuters; 2011: 2394-2397.

59. Erbslöh-Möller B, Dumas A, Roth D, Sfakianakis GN, Bourgoignie JJ. Furosemide- ${ }^{131}$ I-hippuran renography after angiotensin-converting enzyme inhibition for the diagnosis of renovascular hypertension. Am J Med. 1991;90:23-29.

60. Visscher CA, de Zeeuw D, Huisman RM. Effect of chronic ACE inhibition on the diagnostic value of renography for renovascular hypertension: a preliminary report. Nephrol Dial Transplant. 1995;10:263-265. 
61. Fanti S, Dondi M, Guidalotti PL, et al. Bilateral symmetrical induced changes in captopril scintigraphy [abstract]. J Nucl Med. 1998;39(suppl):86P.

62. Stavropoulos SW, Sevigny SA, Ende JF, Drane WE. Hypotensive response to captopril: a potential pitfall of scintigraphic assessment for renal artery stenosis. J Nucl Med. 1999;40:406-411.

63. Fommei E, Ghione S, Hilson AJ, et al. Captopril radionuclide test in renovascular hypertension: a European multicentre study. European Multicentre Study Group. Eur J Nucl Med. 1993;20:617-623.

64. Fommei E, Ghione S, Hilson AJW, et al. Captopril radionuclide test in renovascular hypertension: European Multicentre Study. In: O'Reilly PH, Taylor A, Nally JV, eds. Radionuclides in Nephrourology. Blue Bell, PA: Field and Wood Medical Periodicals, Inc. 1994;33-37.

65. Dondi M, Fanti S, De Fabritiis A, et al. Prognostic value of captopril renal scintigraphy in renovascular hypertension. J Nucl Med. 1992;33:2040-2044.

66. Kahn D, Ben-Haim S, Bushnell DL, et al. Captopril-enhanced ${ }^{99 m}$ Tc-MAG3 renal scintigraphy in subjects with suspected renovascular hypertension. Nucl Med Commun. 1994;15:515-528.

67. Mittal BR, Kumar P, Arora P, et al. Role of captopril renography in the diagnosis of renovascular hypertension. Am J Kidney Dis. 1996;28:209-213.

68. Taylor A. Functional testing: ACEI renography. Semin Nephrol. 2000;20:437-444.

69. Helin KH, Tikkanen I, von Knorring JE, et al. Screening for renovascular hypertension in a population with relatively low prevalence. J Hypertens. 1998;16:1523-1529.

70. Roccatello D, Picciotto G, Rabbia C, et al. Prospective study on captopril renography in hypertensive patients. Am J Nephrol. 1992;12:406-411.

71. Fernandez P, Morel D, Jeandot R, Potaux L, Basse-Cathalinat B, Ducassou D. Value of captopril renal scintigraphy in hypertensive patients with renal failure. J Nucl Med. 1999;40:412-417.
72. Huot SJ, Hansson JH, Dey H, Concato J. Utility of captopril renal scans for detecting renal artery stenosis. Arch Intern Med. 2002;162:1981-1984.

73. Vasbinder GB, Nelemans PJ, Kessels AG, Kroon AA, de Leeuw PW, van Engelshoven JM. Diagnostic tests for renal artery stenosis in patients suspected of having renovascular hypertension: a meta-analysis. Ann Intern Med. 2001;135:401-411.

74. Eriksson P, Mohammed AA, De Geer J, et al. Non-invasive investigations of potential renal artery stenosis in renal insufficiency. Nephrol Dial Transplant. 2010;25:3607-3614.

75. Thorsson O, Bjuvang A, Granerus G. Advantages of standardized criteria for the interpretation of angiotensin-converting enzyme inhibition renography. Nucl Med Commun. 2009;30:449-454.

76. Boubaker A, Prior JO, Meuwly JY, et al. Radionuclide investigations of the urinary tract in the era of multimodality imaging. J Nucl Med. 2006;47:1819-1836.

77. Montini G, Tullus K, Hewitt I. Febrile urinary tract infections in children. N Engl J Med. 2011;365:239-250.

78. Piepsz A, Colarinha P, Gordon I, et al. Guidelines for ${ }^{99 \mathrm{~m}} \mathrm{Tc}-\mathrm{DMSA}$ scintigraphy in children. Eur J Nucl Med. 2001;28:BP37-BP41.

79. Rossleigh MA. Renal infection and vesico-ureteric reflux. Semin Nucl Med. 2007;37:261-268.

80. Biassoni L, Chippington S. Imaging in urinary tract infections: current strategies and new trends. Semin Nucl Med. 2008;38:56-66.

81. Rahbari-Oskoui F, Taylor AT, O'Neill WC. Ultrasonography and nuclear medicine. In: Schrier RW, Coffman TM, Falk RJ, Molitoris BA, Neilson EG, eds. Schrier's Diseases of the Kidney. 9th ed. Philadelphia, PA: Lippincott, Williams and Wilkins; 2013:346-376

82. Taylor A. Radionuclide renography: a personal approach. Semin Nucl Med. 1999:29:102-127. 